\title{
Overall Stability Analysis of Xiluodu High Arch Dam Based on Fine Three-Dimension Numerical Modeling
}

\author{
Tianhui Ma $\mathbb{D}^{1},{ }^{1}$ Zhiqiang Feng $\mathbb{D},{ }^{1}$ Chun'an Tang, ${ }^{1}$ Peng Lin, ${ }^{2}$ and Kedar Prasad Yadav ${ }^{1}$ \\ ${ }^{1}$ State Key Laboratory of Coastal and Offshore Engineering, Dalian University of Technology, Dalian, Liaoning 116024, China \\ ${ }^{2}$ Department of Water Resources and Hydropower Engineering, Tsinghua University, Beijing 100000, China
}

Correspondence should be addressed to Zhiqiang Feng; fengzq136653@mail.dlut.edu.cn

Received 22 November 2020; Revised 25 December 2020; Accepted 15 January 2021; Published 29 January 2021

Academic Editor: Zhigang Zhang

Copyright (c) 2021 Tianhui Ma et al. This is an open access article distributed under the Creative Commons Attribution License, which permits unrestricted use, distribution, and reproduction in any medium, provided the original work is properly cited.

The RFPA3D is used to establish a fine finite element model of 6.63 million elements, which realizes the fine simulation of the stability of the Xiluodu arch dam under layered, overall, multiworking conditions and multistress fields, and the cracking and failure process under overload. The structural design scheme of the arch dam and the corresponding foundation treatment design are evaluated. The model fully reflects the measures of dam shape structure design, angle fitting structure design, and foundation concrete replacement in the Xiluodu arch dam technical design stage. The RFPA3D adopts the mesoelement elastic damage model, which considers the Mohr-Coulomb criterion of shear fracture and the maximum tensile failure criterion, and assumes that the mechanical properties of the element satisfy Weibull distribution to consider its heterogeneity. The simulation results show that, under normal load conditions, the dam foundation surface after comprehensive reinforcement has better overall stability, the stress and deformation of the dam body have good symmetry, and the overload factor of crack initiation under overload calculation $K 1=2 \mathrm{P} 0$ ( $\mathrm{P} 0$ is normal water load), the nonlinear deformation overload factor $K 2=3.5-4 \mathrm{P} 0$, and the limit load factor $K 3=7.5-8.0 \mathrm{P} 0$, dam safety can be satisfied. The RFPA3D is used to establish a superlarge fine model to study the overall stability of the high arch dam, which provides an effective method for analysis and research of other large hydraulic projects in the world.

\section{Introduction}

A series of major projects related to national economic construction in China, such as water conservancy and hydropower industry, tend to be large-scale, comprehensive, and complex. A large number of dam foundation-bank structures that are complete, in process, or proposed are generally facing the challenges of construction and operational safety under complex, unpredictable, and extreme load conditions. Among super-high dams, the arch dams transfer loads to the dam foundations and abutments through the effect of the beam and the arching effect, so that the dam body is mainly compressed, and hence, the compressive performance of concrete materials can be fully realized. It has become an extremely beneficial dam type of super-high dams because of its advantages of high safety, strong seismic capacity, large dam discharge, and small concrete quantities [1-5]. However, as most of the load is transferred to the rock on both sides of the dam, high stability and strength of the rock are required. If the geological conditions of the foundation are not good or the symmetry is poor, the arch dam will be prone to stress concentration, dam instability, and other problems, which can result in cracking and even damage to the dam body. The safe operation of dams has a profound impact on social energy efficiency and the lives of downstream residents. There have been many incidents of arch dam damage in the world $[6,7]$, which have greatly hindered the safe operation of the project. Therefore, it is particularly important to reasonably evaluate the stability of the arch dams in the design.

At present, there are two main methods to study the overall stability of dams: three-dimensional geomechanical model test and numerical simulation analysis [8-14]. 
Among various numerical simulation methods, the threedimensional nonlinear finite element method is widely used in the stability analysis of high arch dam; using a threedimensional nonlinear finite element method to calculate the deformation and stress of the arch dam can well simulate the constitutive relationship and load and boundary conditions of the complex rock and can better reflect the complexity of geological structure and the influence of engineering measures on dam structure. Therefore, with the development of computer technology and the popularity of general finite element software, finite element analysis technology has been more and more widely used in solving complex hydropower engineering problems and achieved good engineering results. For example, Yang et al. [15] tried to solve large finite element equations by an iterative method in the three-dimensional finite element analysis of the Geheyan gravity arch dam in 1989 and obtained reasonable calculation results. Shen et al. [16] solved the minimum safety factor and the position of the corresponding potential sliding surface during the excavation of Xiaolangdi high slope by using the three-dimensional finite element analysis method, and the results were confirmed by actual construction. Chen et al. [17] and Chen et al. [18], respectively, carried out a finite element analysis on the abutment rock mass stability and the dam heel cracking risk of the Xiaowan high arch dam. Wang et al. [19] simulated and analyzed the stress state of the Ertan arch dam during operation. According to the results of numerical simulation and model test, Zhang et al. [20] analyzed the displacement and stress distribution, failure mechanism, and overall stability of the arch dam; the results are in good agreement. Pei et al. [21] simulated the construction process and impoundment process of the Lizhou RCC arch dam and analyzed the stress deformation behavior and development law of the dam body in the real working state during the impoundment process. These applications show that the finite element numerical simulation analysis has obvious advantages in studying the stress, displacement, and failure characteristics of high arch dams and has become an effective way to study the dam design, reinforcement, and stability evaluation of high arch dams.

The accuracy of finite element analysis will be affected by the selection of reasonable constitutive relations. Arch dams are usually built into geologically complex mountains and valleys and form an interactive system with dam foundation and dam abutments. As the main engineering materials, rock and concrete are heterogeneous quasi-brittle materials with complex mechanical properties. The researchers have made in-depth discussions on their constitutive relations from phenomenology and physical mechanisms, including strength theory, plastic constitutive theory, damage constitutive theory, and distributed fracture mechanics constitutive theory [22-26]. It has been widely recognized that the fracture and failure process of rock or concrete is actually the whole process of microcracks' generation and development until the formation of the transfixion zone under load. In the past, the constitutive relations of nonlinear finite elements only grasped the "nonlinear" characteristics of material deformation from the macrolevel and participated in the analysis and calculation as an element's attribute, which ignored the inhomogeneity of micromedium parameters, so there is no macromicro difference in the results. In fact, due to the extreme heterogeneity of these materials, their properties at the microlevel are very different from the macrolevel. In order to fully consider the nonlinearity and heterogeneity during the fracture process of rock or concrete, Tang et al. proposed a new numerical simulation method "RFPA (Rock Failure Process Analysis) Method" [27-33] based on the basic theory of finite element, to explain the structural fracture process with statistical damage theory, and the basic principle of strength reduction method $[34,35]$ was introduced to analyze the stability of geotechnical engineering [36]. It is proved that the method can be used to deal with geotechnical engineering under complex geological conditions effectively.

In addition, the number of grids affects the accuracy of calculation results and the size of the calculation scale. In order to make the element size in numerical simulation reflect the basic microscopic properties of the medium, the RFPA3D code is used to establish the superlarge model of the Xiluodu high arch dam with full hexahedron element (6, 632, 192 elements, 6,893,485 nodes, more than 20 million degrees of freedom). The large-scale parallel computing cluster [37] is used to realize the fine simulation of the dam under layered, overall, multiworking conditions and multistress fields. On the basis of fully reflecting the geological conditions after the actual excavation of the Xiluodu arch dam, the corresponding structural design and foundation treatment measures, the deformation and stress characteristics of the dam body, and abutment rock mass under several different load combinations are studied. Through the application of overload, the overload coefficient, yield, and cracking conditions of each failure stage are obtained to analyze the overload capacity of the arch dam. According to the analysis results, the overall stability and safety of the arch dam under the structural design and foundation treatment design scheme are demonstrated, and the overall safety of the arch dam under the current implementation scheme is comprehensively evaluated, and the results provide a basis for the structural design and foundation treatment design of the Xiluodu high arch dam.

\section{Engineering Background}

The Xiluodu hydropower station is located in Xiluodu gorge, which is adjacent to Leibo County in Sichuan Province and Yongshan County in Yunnan Province. This is the third cascade in the development plan of the Jinsha River section. The double-curvature arch dam is selected as the dam type (the centerline of the arch dam is $\mathrm{N} 48.2^{\circ} \mathrm{W}$ ), with a crest elevation of $610.0 \mathrm{~m}$, a foundation surface elevation of $332.0 \mathrm{~m}$, and a maximum dam height of $278.0 \mathrm{~m}$, which bears a huge water thrust of about 13 million tons, requiring the foundation to have the corresponding bearing capacity. The total amount of engineering concrete is 12.96 million $\mathrm{m}^{3}$, of which about 7 million $\mathrm{m}^{3}$ is dam concrete. The normal water level of the reservoir is $600.00 \mathrm{~m}$, and the corresponding downstream water level is $378.00 \mathrm{~m}(381.46 \mathrm{~m}$ for 
normal operation of 18 units); the dead water level is $540.00 \mathrm{~m}$, and the corresponding downstream water level is $378.00 \mathrm{~m}$; the total storage capacity is 11.57 billion $\mathrm{m}^{3}$, and the regulated storage capacity is 641.6 billion $\mathrm{m}^{3}$. This project is a giant hydropower station that mainly generates electricity and has comprehensive utilization benefits such as sand retaining, flood control, and improving downstream shipping.

There are abundant mountains on both sides of the Xiluodu double-curvature arch dam, with a steep valley slope. The valley section is symmetrical " $U$ ", with the left bank slope of $40^{\circ} \sim 75^{\circ}$ and the right bank slope of $55^{\circ} \sim 75^{\circ}$. The rock property of the dam site area is single, and the bedrock of the valley slope and the riverbed is the continental basic volcanic rock flow with the intermittently multistage eruption of Emeishan basalt $(\mathrm{P} 2 \beta)$, which is divided into 14 rock flow layers, generally $25-40 \mathrm{~m}$ thick. The representative lithology mainly includes porphyry basalt (1, 6 layers), microcrystalline basalt (2, 5, 9-14 layers), and phenocryst basalt $(3,4,7,8$ layers), which are distributed in the lower part of the flow layer; basaltic breccia (agglomerate) lava and a small amount of volcanic breccia and basaltic tuff are distributed in the upper part of most flow layers; the lithology changes gradually from the top to the bottom.

Compared with the design requirements and acceptance standards, the rock mass quality of the riverbed under natural conditions is insufficient. Therefore, it is necessary to strengthen consolidation grouting and adopt structural forms, expand the stress area of the foundation, and improve the homogeneity of rock mass and the stiffness of the foundation, so as to meet the requirements of dam construction.

\section{Numerical Model Analysis}

3.1. Introduction to the Model. A three-dimensional model is adopted in this calculation. Centered at the dam axis, the calculation range is as follows: the upstream length is about 1 times the height of the dam, the downstream length is about 2.5 times the height of the dam, the banks are near twice the height of the dam, and the simulated depth of the dam foundation is almost the same as the height of the dam. The mesh generation is carried out according to the drawings provided by the Chengdu Survey and Design Institute of China Hydropower Consulting Group, and the total simulation range is $1800 \times 1000 \times 660 \mathrm{~m}$. Eight-node hexahedron elements are adopted in the grid, with a total number of $6,632,192$ elements, a total number of $6,893,485$ nodes, and a total number of 2,692,032 dam elements. The computational grid is shown in Figures 1 and 2.

Combined with the current situation of the Xiluodu foundation rock mass, the rock mass parameters are evaluated by the method of layered, segmented, zoned, and graded benchmarking, and on this basis, various rock masses, dislocation zones $\mathrm{C} 9, \mathrm{C} 8, \mathrm{C} 7, \mathrm{Lc} 6, \mathrm{Lc} 5, \mathrm{C} 3$, and $\mathrm{C} 2$, and weak interlayer $\mathrm{P} 2 \beta \mathrm{n}$ are simulated, and the distribution characteristics are shown in Table 1 and Figure 3. The foundation concrete replacement and dam toe treatment are

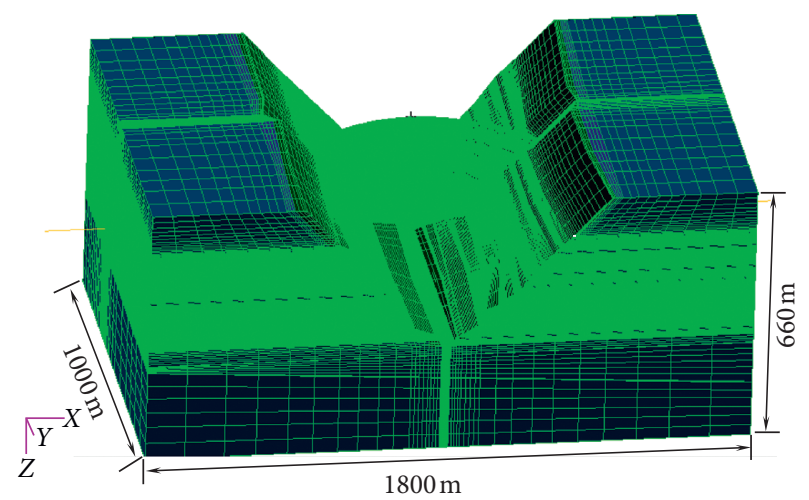

Figure 1: Computational grid diagram (Overall Diagram).

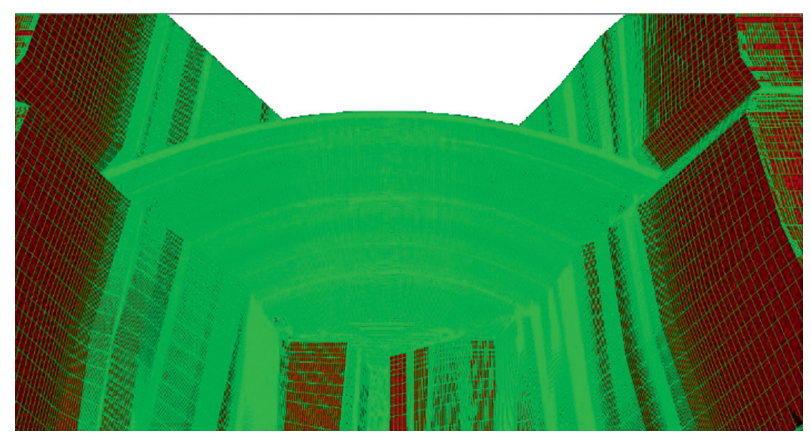

FIGURE 2: Computational grid diagram (Enlarged Partial Diagram).

shown in Figure 4. Concrete replacement: the replacement and backfill treatment are carried out for the interlaminar dislocation zone on the banks of the dam foundation at EL 510-610 m, grade IV1 rock mass exposed above the EL $560 \mathrm{~m}$, grade IV 1 and class III2 exposed below the EL $560 \mathrm{~m}$, the staggered zone in the interlayer between the EL $400-510 \mathrm{~m}$ and the strongly weathered interlayer, the grade IV1 rock mass exposed on the foundation surface, and the grade III2 rock mass exposed at the middle elevation and lower elevation of the foundation surface. Because the broken rock mass and dislocation zone $\mathrm{C} 3$ are exposed at $\mathrm{EL}$ $330.00-350.00 \mathrm{~m}$ on the left bank of the dam foundation, it is grooved. The strongly weathered interlayer in the middle dislocation zone of the $\mathrm{P} 2 \beta \mathrm{n}$ layer is treated with a composite replacement plug. The exposed IV 1 and III 2 rock masses on the riverbed are treated by displacement excavation. The minimum excavation elevation is EL $324.5 \mathrm{~m}$, and the depth is about $7 \mathrm{~m}$. The depth of replacement excavation shall be adjusted locally according to the geological exposure of the site.

The RFPA3D adopts the mesoelement elastic damage model [28], which considers the Mohr-Coulomb criterion of shear fracture and the maximum tensile failure criterion, and assumes that the mechanical properties of the element satisfy Weibull distribution to consider its heterogeneity, so as to reveal the macroscopic nonlinearity of quasi-brittle materials such as rock or concrete from the simple elasticbrittle constitutive relation at the mesolevel. The elasticbrittle constitutive relation of primitive under uniaxial stress is shown in Figure 5. 
TABLE 1: Characteristics of dislocation zone in the interlayer of the dam area.

\begin{tabular}{|c|c|c|c|c|c|c|c|c|}
\hline \multirow{2}{*}{ Place } & \multirow{2}{*}{ Weak zone } & \multirow{2}{*}{$\mathrm{EL}(\mathrm{m})$} & \multirow{2}{*}{ Thickness (m) } & \multirow{2}{*}{ Attitude } & \multicolumn{2}{|c|}{ Shear resistance } & \multicolumn{2}{|c|}{ Shear } \\
\hline & & & & & $\mathrm{f}^{\prime}$ & $\mathrm{c}^{\prime}(\mathrm{MPa})$ & $\mathrm{f}$ & $\mathrm{C}(\mathrm{MPa})$ \\
\hline \multirow{9}{*}{ Left bank } & \multirow{2}{*}{ C9 } & \multirow{2}{*}{536} & \multirow{2}{*}{0.5} & \multirow{2}{*}{$\mathrm{N} 25^{\circ} \mathrm{W} / \mathrm{NE} \angle 4^{\circ}$} & 0.35 & 0.05 & 0.30 & 0 \\
\hline & & & & & 0.40 & 0.07 & 0.34 & 0 \\
\hline & \multirow{2}{*}{$\mathrm{C} 8$} & \multirow{2}{*}{513} & \multirow{2}{*}{0.5} & \multirow{2}{*}{$\mathrm{N} 35^{\circ} \mathrm{W} / \mathrm{NE} \angle 5^{\circ}$} & 0.35 & 0.05 & 0.30 & 0 \\
\hline & & & & & 0.44 & 0.10 & 0.37 & 0 \\
\hline & $\mathrm{C} 7$ & 479 & 0.6 & $\mathrm{~N} 25 \sim 35^{\circ} \mathrm{W} / \mathrm{NE} \angle 4 \sim 7^{\circ}$ & 0.55 & 0.25 & 0.47 & 0 \\
\hline & Lc6 & 403 & 0.6 & $\mathrm{~N} 20^{\circ} \sim 40^{\circ} \mathrm{WNE} \angle 8^{\circ} \sim 11^{\circ}$ & 0.44 & 0.10 & 0.37 & 0 \\
\hline & Lc5 & 380 & 0.6 & $\mathrm{~N} 20^{\circ} \sim 30^{\circ} \mathrm{WNE} \angle 4^{\circ} \sim 7^{\circ}$ & 0.55 & 0.25 & 0.47 & 0 \\
\hline & \multirow{2}{*}{$\mathrm{C} 3$} & \multirow{2}{*}{339} & \multirow{2}{*}{0.5} & \multirow{2}{*}{$\mathrm{N} 18^{\circ} \sim 23^{\circ} \mathrm{WNE} \angle 5^{\circ} \sim 8^{\circ}$} & 0.43 & 0.08 & 0.37 & 0 \\
\hline & & & & & 0.44 & 0.10 & 0.37 & 0 \\
\hline \multirow{10}{*}{ Right bank } & \multirow{2}{*}{ C9 } & \multirow{2}{*}{562} & \multirow{2}{*}{0.5} & \multirow{2}{*}{$\mathrm{N} 36^{\circ} \mathrm{E} / \mathrm{SE} \angle 2 \sim 5^{\circ}$} & 0.35 & 0.05 & 0.30 & 0 \\
\hline & & & & & 0.4 & 0.07 & 0.34 & 0 \\
\hline & \multirow{2}{*}{$\mathrm{C} 8$} & \multirow{2}{*}{536} & \multirow{2}{*}{0.5} & \multirow{2}{*}{$\mathrm{N} 38^{\circ} \mathrm{E} / \mathrm{SE} \angle 4^{\circ}$} & 0.43 & 0.08 & 0.37 & 0 \\
\hline & & & & & 0.44 & 0.10 & 0.37 & 0 \\
\hline & \multirow{2}{*}{$\mathrm{C} 7$} & \multirow{2}{*}{497} & \multirow{2}{*}{0.6} & \multirow{2}{*}{$\mathrm{N} 30 \sim 35^{\circ} \mathrm{E} / \mathrm{SE} \angle 4 \sim 6^{\circ}$} & 0.43 & 0.08 & 0.37 & 0 \\
\hline & & & & & 0.55 & 0.25 & 0.47 & 0 \\
\hline & Ick & 424 & 06 & $\mathrm{~N} 30^{\circ} \sim 40^{\circ} \mathrm{FSF} / 8^{\circ} \sim 10^{\circ}$ & 0.43 & 0.08 & 0.37 & 0 \\
\hline & LCO & 424 & 0.0 & N $30 \sim 40$ ESE $\angle 8 \sim 10$ & 0.44 & 0.10 & 0.37 & 0 \\
\hline & Lc5 & 385 & 0.6 & $\mathrm{~N} 30^{\circ} \sim 40^{\circ} \mathrm{ESE} \angle 8^{\circ} \sim 10^{\circ}$ & 0.55 & 0.25 & 0.47 & 0 \\
\hline & $\mathrm{C} 3$ & 345 & 0.5 & $\mathrm{~N} 24^{\circ} \mathrm{E} / \mathrm{SE} \angle 4^{\circ} \sim 5^{\circ}$ & 0.50 & 0.17 & 0.42 & 0 \\
\hline & $\mathrm{C} 2$ & 302 & 0.5 & $\mathrm{~N} 25-30^{\circ} \mathrm{W} / \mathrm{SW} \angle 5-10^{\circ}$ & 0.35 & 0.05 & 0.35 & 0 \\
\hline River bed & $\mathrm{P} 2 \beta \mathrm{n}$ & 240 & 1.8 & $\mathrm{~N} 25-30^{\circ} \mathrm{W} / \mathrm{SW} \angle 5-10^{\circ}$ & 0.35 & 0.05 & 0.35 & 0 \\
\hline
\end{tabular}

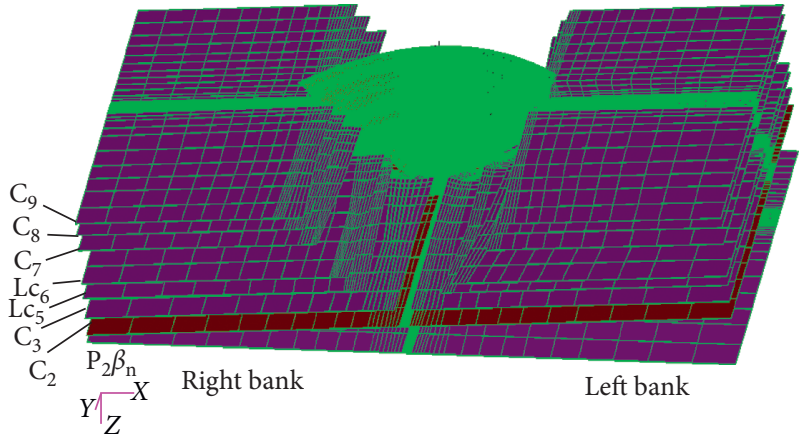

FIgURE 3: Relationship between the dislocation zone and the dam body in the interlayer.

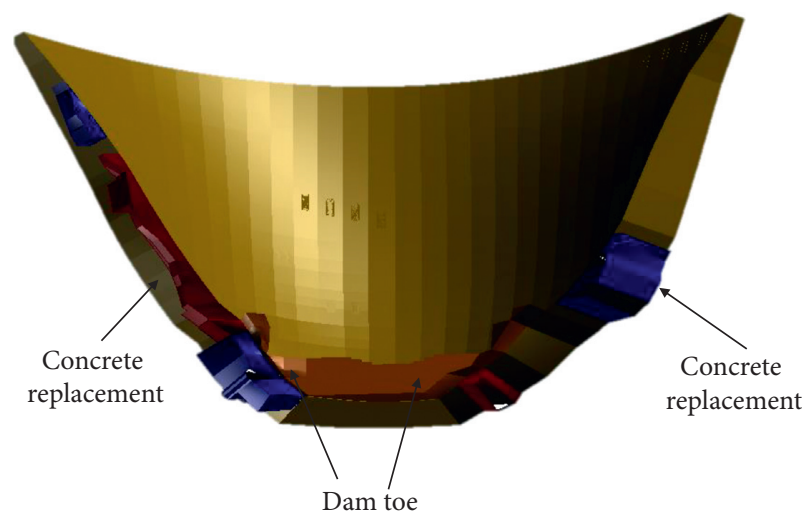

FIGURE 4: Relationship between foundation concrete replacement and dam toe (downstream).

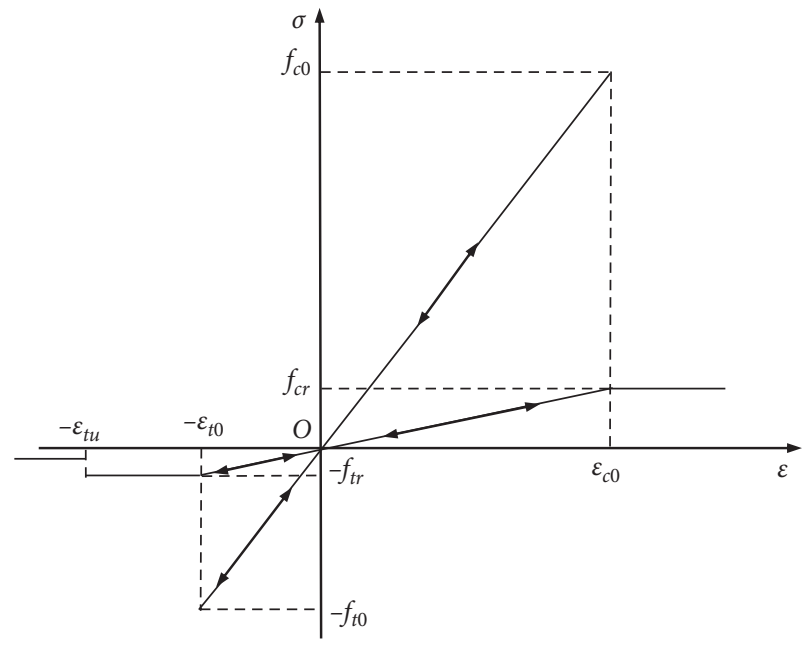

FIGURE 5: Elastic-brittle constitutive relation of the element under uniaxial stress state.

For quasi-brittle materials such as rock, especially in the case of special mesoscale, tensile damage mainly occurs in the element. Therefore, if the mesoelement satisfies both the shear failure criterion and tensile failure criterion, the tensile criterion takes precedence.

The Mohr-Coulomb criterion with tensile failure criterion is expressed as follows:

$$
\left\{\begin{array}{l}
\sigma_{1}-\lambda \sigma_{3} \geq \sigma_{c}, \sigma_{1}>\sigma_{c}-\lambda \sigma_{t} \\
\sigma_{3} \leq-\sigma_{t}, \quad \sigma_{1} \leq \sigma_{c}-\lambda \sigma_{t}
\end{array}\right.
$$

where $\lambda=(1+\sin \varphi) /(1-\sin \varphi)=\tan ^{2} \theta ; \theta$ is the angle of rupture. 
3.2. Material Parameters. The actual monitoring value of dam deformation is usually very different from the original design calculation value, and the mechanical parameters of the rock foundation in the reservoir area also vary greatly. These factors have a great influence on the deformation of the dam body and rock foundation. Therefore, it is necessary to use measured data, combined with numerical analysis and calculation, to carry out inverse analysis on the elastic modulus $E c$ of the dam body, the deformation modulus Er of the dam bedrock foundation, and the deformation modulus $E b$ of the reservoir rock foundation and deduce the actual deformation modulus by this method. Table 2 shows the mechanical parameters of Xiluodu materials.

3.3. Calculation Conditions. In this paper, the RFPA3D code is used for finite element numerical calculation, and only the self-weight stress field is considered for crustal stress. As for water load, the upstream check flood level and corresponding downstream water level are $607.00 \mathrm{~m}$ and $414.61 \mathrm{~m}$, and the upstream design flood level and corresponding downstream water level are $600.70 \mathrm{~m}$ and $409.78 \mathrm{~m}$. The upstream silt elevation is $490.00 \mathrm{~m}$, the floating bulk density of the silt is $0.5 \mathrm{t} / \mathrm{m}^{3}$, and the internal friction angle of the silt is $0^{\circ}$. The temperature load of the dam body is shown in Table 3, and the linear expansion coefficient of dam concrete is $1.0 \times 10-5 /{ }^{\circ} \mathrm{C}$. The calculation consists of 16 calculation conditions, as shown in Tables 4 and 5 .

\section{Dam Displacement and Stress Analysis}

4.1. Dam Displacement Analysis. In this paper, the displacement characteristics of the dam body along the river and transverse the river were analyzed, the working conditions include basic load conditions 4-11, and special load conditions $12-16$. The results show that the overall stiffness of the dam foundation after reinforcement is good. Figure 6 shows the displacement distribution along the river of Xiluodu arch dam under conditions 4 and 6.

Taking working condition 4 as an example, the results show that the maximum displacement of the crown along the river was $104.356 \mathrm{~mm}$, located at EL $585 \mathrm{~m}$. The maximum displacement of the left arch abutment along the river was $27.612 \mathrm{~mm}$, at the downstream surface EL $345 \mathrm{~m}$. The maximum displacement of the right arch abutment along the river was $25.617 \mathrm{~mm}$, at the downstream surface EL360 $\mathrm{m}$. The maximum displacement of the arch dam foundation is $25.541 \mathrm{~mm}$, which is located at the right arch abutment EL $440 \mathrm{~m}$, and the relative displacement of the disturbed belt is relatively small. The transverse displacement of the downstream dam surface was toward the mountains. The upstream surface varied from EL $480 \mathrm{~m}$ to EL $440 \mathrm{~m}$, and the displacement of the upper part points to the mountains, and the displacement below EL $475 \mathrm{~m}$ points to the dam in the transverse direction with the maximum displacement of $2.203 \mathrm{~mm}$. Figure 6 shows the displacement characteristic curve of the arch dam under a normal load condition (condition 4).

The displacement characteristics under each condition calculated by RFPA3D code are as follows:

(1) Along the river, the maximum displacement of the Xiluodu arch dam under various working conditions was located at the downstream arch crown, the displacement of the two arch abutments was equal, the displacement of the left abutment was slightly larger than that of the right abutment, and the displacement symmetry of dam body was good. Under one to five times of normal water load, the relationship between displacement and overload coefficient is basically linear, which indicates that the deformation of dam structure can still keep a certain linear working state. Figure 7 shows the displacement comparison of the dam abutments and arch crown under 1-5 times normal water load (other loads are the same).

(2) Under different working conditions, the displacement characteristics of the downstream surface of the dam body on the transverse direction of the river were similar, and all of them were toward the mountains, so the dam body had good symmetry. Under the basic load combination, transverse displacement of the upstream surface changed at EL $400 \mathrm{~m}$-EL $520 \mathrm{~m}$, the upper abutments deformed toward the mountains, and the lower abutments deformed toward the dam, so it could be predicted that the compressive stress was larger in this part.

(3) The temperature effect is shown in Figure 8. Under the working condition of temperature rise, the deformation of the two arch abutments increased toward both the mountains and rivers, while the transverse deformation and deformation along the river at the arch crown decreased, which was beneficial to the stability of the arch crown and unfavorable to the stability of the arch abutments.

It can be seen from the calculation results that, under the basic load combinations, the dam surface was basically in a relatively uniform compression state. With the increase of load, the tensile stress first occurred at the dam crest. The maximum tensile stress on the downstream surface was $-1.119 \mathrm{MPa}$ under working condition 4 , and the maximum tensile stress under other working conditions did not exceed $-0.5 \mathrm{MPa}$. The compressive stress at the two arch abutments of the downstream surface was moderate, and the maximum compressive stress appeared at the arch abutments, mainly at EL $350 \mathrm{~m}$-EL $380 \mathrm{~m}$. The compressive stress at the left arch abutment and that at the right arch abutment were equivalent, and the compressive stress at the left arch abutment was slightly larger. The characteristic stress values of arch dams under different load combinations are shown in Tables 6 and 7 .

As one of the main loads of arch dams, temperature load has an important influence on the distribution of the stress 
TABle 2: Material mechanical parameters of Xiluodu arch dam.

\begin{tabular}{|c|c|c|c|c|c|}
\hline \multirow[t]{2}{*}{ Material } & \multirow[t]{2}{*}{ Unit weight $\left(\mathrm{t} / \mathrm{m}^{3}\right)$} & \multirow[t]{2}{*}{ Deformation modulus (GPa) } & \multirow[t]{2}{*}{ Poisson's ratio } & \multicolumn{2}{|c|}{$\begin{array}{l}\text { Effective shear } \\
\text { strength }\end{array}$} \\
\hline & & & & $\mathrm{C}^{\prime}(\mathrm{MPa})$ & $\mathrm{F}^{\prime}$ \\
\hline Dam concrete & 2.40 & 24 & 0.167 & 5.0 & 1.70 \\
\hline Diversion bottom hole concrete & 2.40 & 32 & 0.167 & 5.0 & 1.70 \\
\hline Class II rock & 2.85 & 16.5 & 0.20 & 2.5 & 1.35 \\
\hline III1 & 2.85 & 11.5 & 0.25 & 2.20 & 1.22 \\
\hline III2 & 2.75 & 5.5 & 0.28 & 1.4 & 1.2 \\
\hline IV1 & 2.6 & 3.0 & 0.30 & 1.0 & 1.02 \\
\hline IV2 & 2.6 & 1.0 & 0.30 & 0.50 & 0.70 \\
\hline $\mathrm{V}$ & 2.2 & 0.5 & 0.35 & 0.05 & 0.35 \\
\hline Left bank C9 & 2.4 & 0.5 & 0.3 & 0.07 & 0.4 \\
\hline Right bank C9 & 2.4 & 0.5 & 0.3 & 0.06 & 0.4 \\
\hline Left bank C8 & 2.4 & 0.8 & 0.3 & 0.1 & 0.44 \\
\hline Right bank C8 & 2.4 & 0.9 & 0.3 & 0.1 & 0.44 \\
\hline $\mathrm{C} 8$ & 2.4 & 3 & 0.3 & 0.25 & 0.55 \\
\hline Left bank C7 & 2.4 & 1.7 & 0.3 & 0.2 & 0.55 \\
\hline Right bank C7 & 2.4 & 1.3 & 0.3 & 0.2 & 0.5 \\
\hline Left bank LC6 & 2.4 & 0.8 & 0.3 & 0.08 & 0.44 \\
\hline Right bank LC6 & 2.4 & 0.9 & 0.3 & 0.08 & 0.44 \\
\hline Left bank LC5 & 2.4 & 0.8 & 0.3 & 0.09 & 0.44 \\
\hline Right bank LC5 & 2.4 & 0.8 & 0.3 & 0.08 & 0.44 \\
\hline $\mathrm{C} 3$ & 2.4 & 0.8 & 0.3 & 0.17 & 0.5 \\
\hline $\mathrm{C} 2$ & 2.4 & 0.5 & 0.3 & 0.05 & 0.35 \\
\hline $\mathrm{P} 2 \beta \mathrm{n}$ & 2.4 & 1.5 & 0.3 & 0.05 & 0.35 \\
\hline
\end{tabular}

TABLe 3: Temperature load of normal water level $\left({ }^{\circ} \mathrm{C}\right)$.

\begin{tabular}{|c|c|c|c|c|c|c|c|c|c|c|}
\hline \multicolumn{11}{|c|}{ Height (m) } \\
\hline \multicolumn{2}{|l|}{ Item } & 610.0 & 590.0 & 560.0 & 520.0 & 480.0 & 440.0 & 400.0 & 360.0 & 332.0 \\
\hline \multirow{2}{*}{ Designed temperature drop $\left({ }^{\circ} \mathrm{C}\right)$} & $\mathrm{Tm}$ & 2.72 & 2.38 & 2.48 & 1.86 & 2.80 & 2.83 & 3.85 & 3.14 & 2.25 \\
\hline & $\mathrm{Td}$ & 0.00 & 2.11 & 6.37 & 8.42 & 9.06 & 9.28 & 9.42 & 8.57 & 7.50 \\
\hline \multirow{2}{*}{ Designed temperature rise $\left({ }^{\circ} \mathrm{C}\right)$} & $\mathrm{Tm}$ & 8.65 & 5.39 & 4.09 & 2.93 & 3.63 & 3.52 & 4.50 & 3.52 & 2.25 \\
\hline & $\mathrm{Td}$ & 0.00 & 4.97 & 11.4 .0 & 13.08 & 13.23 & 13.23 & 13.11 & 10.75 & 7.50 \\
\hline
\end{tabular}

field, and the change of dam body temperature is an important reason for concrete cracks. By comparing and analyzing the characteristic stress law of arch dam under eight working conditions of $4,5,10,11$, and $13-16$, the results show that due to the constraint of the abutment rock mass and foundation on the dam body, the temperature rise caused tension on the upstream surface of the arch dam, which makes the upstream surface more prone to cracks, and the downstream surface of the dam had a tendency of squeezing inward.

\subsection{Analysis of Stress Displacement and Point Safety of the Foundation}

4.2.1. Displacement of Abutment Rock Mass. The deformation of the dam abutment rock mass can reflect the stiffness harmony between the rock mass on both banks and the dam. Excessive deformation of the dam abutment will lead to unreasonable stress distribution of the dam body, which will affect the overall stability of the dam body. The calculation of the RFPA3D code shows that the displacement of the dam abutment rock mass along the river mainly occurred near the arch abutments, and the maximum displacement occurred in the middle and lower parts of the downstream arch abutments.
Taking the displacement of the dam abutment rock mass under normal load condition (condition 4) as an example, the displacement of the upstream dam abutments along the river decreased gradually from the bottom elevation to the top, while the displacement of the downstream dam abutments decreased from middle elevation to the top and the bottom, the displacement difference between the top and bottom elevation was small, and the maximum displacement difference was not greater than $12.5 \mathrm{~mm}$. The transverse displacement of the two banks was basically symmetrical, which was larger in the middle elevation and decreased toward the top and bottom gradually. The maximum displacement of the left bank was $10.744 \mathrm{~mm}$, located at EL $565 \mathrm{~m}$, and the maximum displacement of the right bank was $-9.835 \mathrm{~mm}$, located at EL $525 \mathrm{~m}$ (as shown in Figures 9 and $10)$.

4.2.2. Foundation Stress. The following can be obtained from the principal stress distribution of the foundation under working conditions 4 to 16 (Figures 11 and 12 show the principal stress distribution of the foundation under normal working conditions):

(1) The calculation results of the basic load combinations (working conditions $4,5,10$, and 11 ) show that 


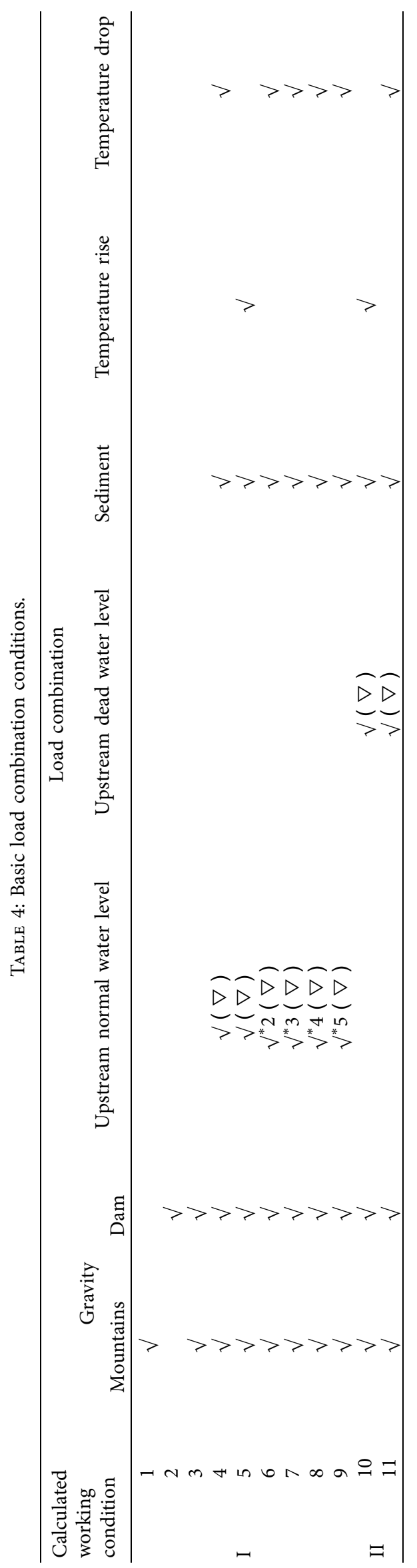




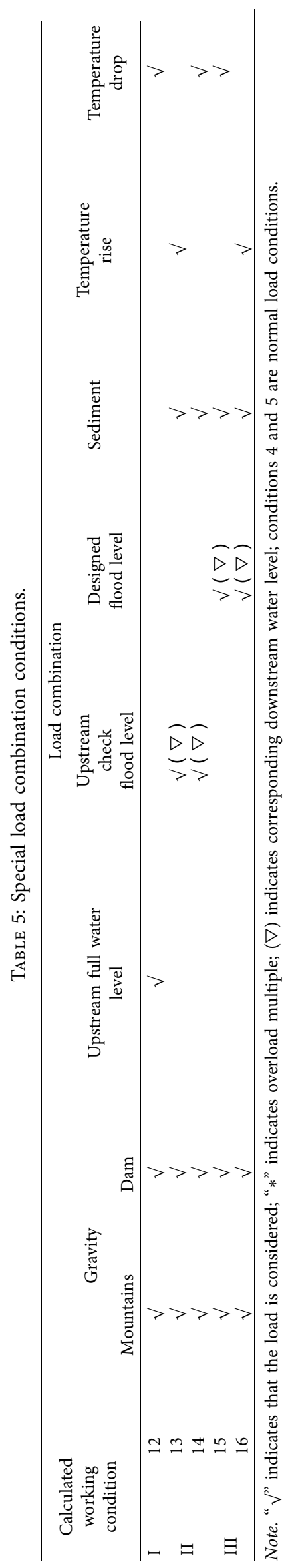




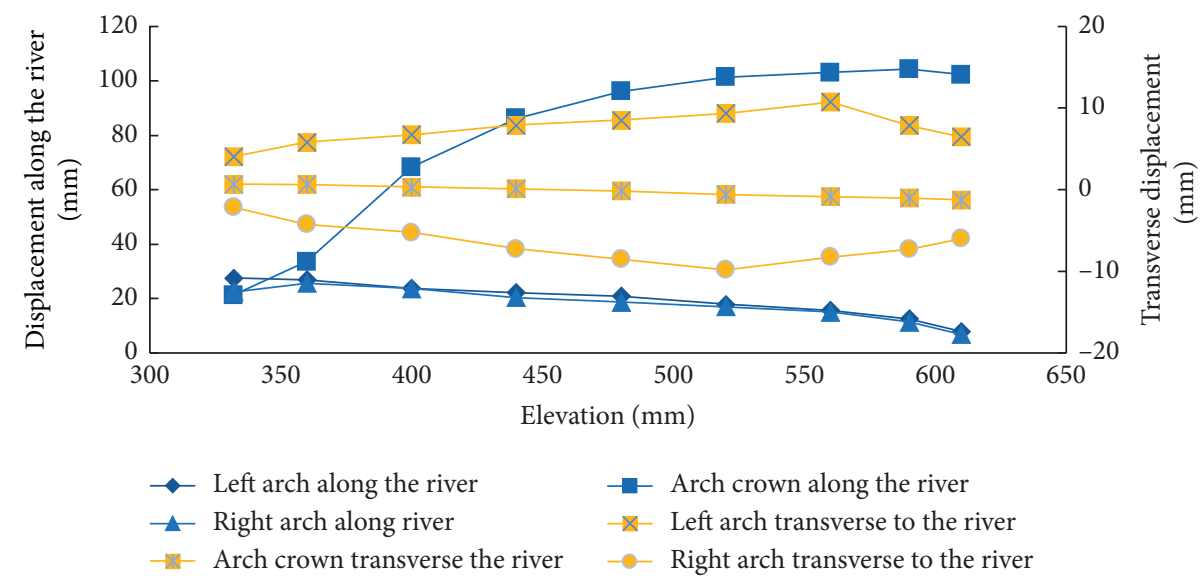

Figure 6: Displacement characteristic curve of the arch dam under normal load combination.

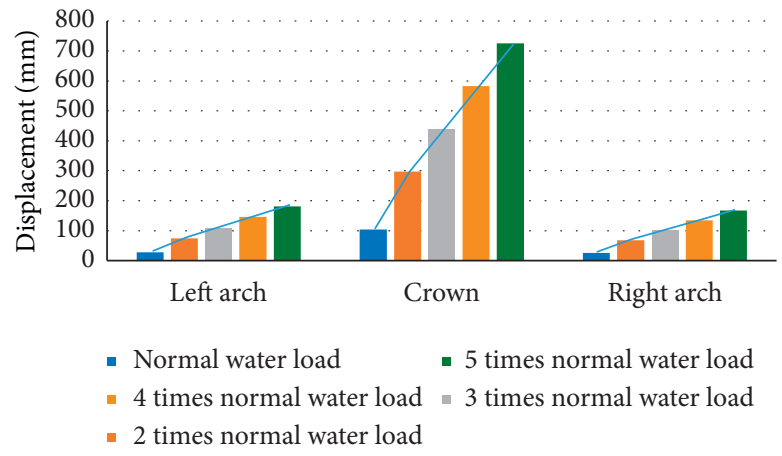

Figure 7: Comparison of the displacement of the arch dam along the river under different load combinations.

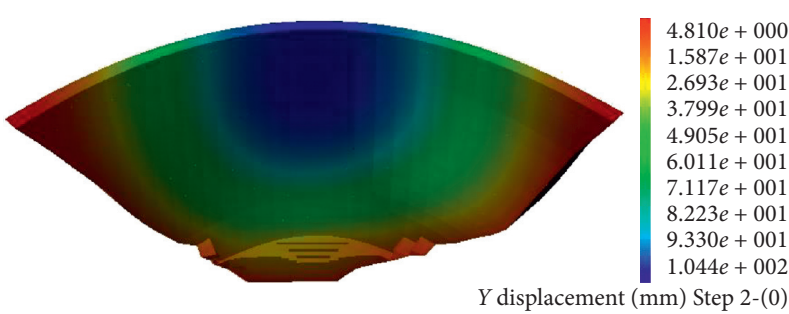

(a)

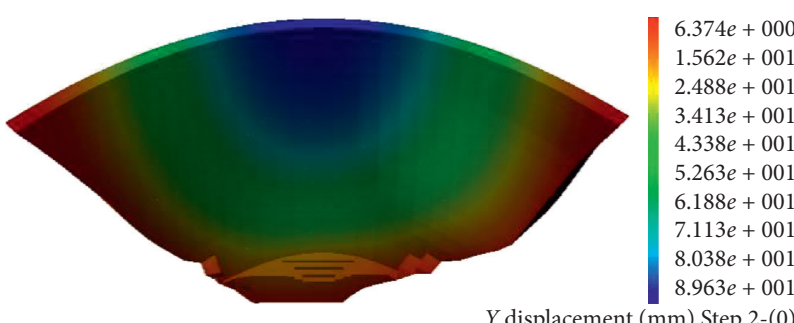

(c)

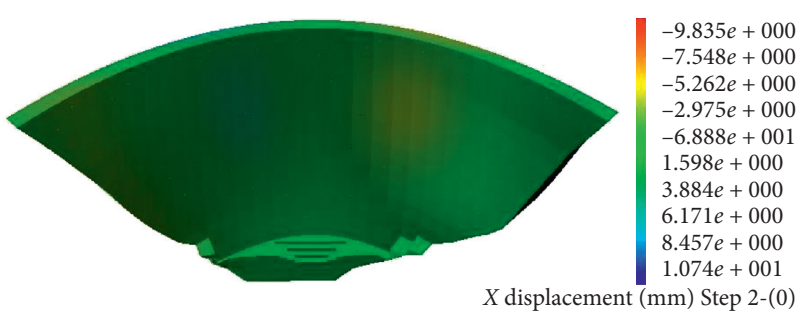

(b)

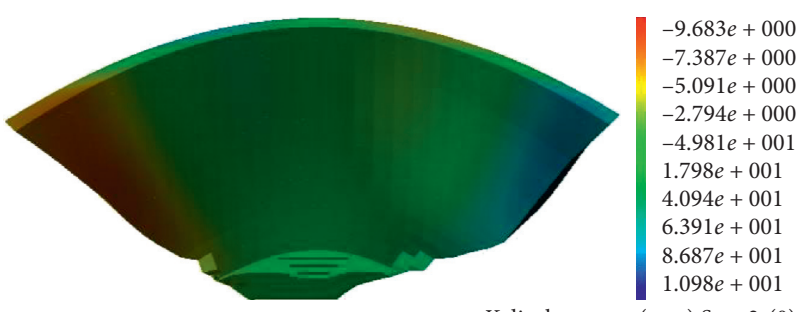

(d)

Figure 8: Comparison of the displacement distribution of the Xiluodu arch dam under conditions 4 and 5 . Stress analysis of dam body. (a) Downstream river direction (condition 4). (b) Downstream transverse direction (condition 4). (c) Downstream river direction (condition 5). (d) Downstream transverse direction (condition 5). 
TABLE 6: Characteristic stress value and position of the arch dam under basic load combination (unit: MPa).

\begin{tabular}{|c|c|c|c|c|c|c|}
\hline \multirow[b]{2}{*}{ Condition } & \multicolumn{2}{|c|}{ Upstream surface } & \multicolumn{2}{|c|}{ Downstream surface } & \multicolumn{2}{|c|}{ Dam toe } \\
\hline & $\begin{array}{l}\text { Maximum } \\
\text { tensile stress }\end{array}$ & $\begin{array}{c}\text { Maximum } \\
\text { compressive stress }\end{array}$ & $\begin{array}{l}\text { Maximum } \\
\text { tensile stress }\end{array}$ & $\begin{array}{c}\text { Left abutment } \\
\text { maximum compressive } \\
\text { stress }\end{array}$ & $\begin{array}{c}\text { Right abutment } \\
\text { maximum compressive } \\
\text { stress }\end{array}$ & $\begin{array}{c}\text { Maximum } \\
\text { compressive stress }\end{array}$ \\
\hline $\begin{array}{l}\text { Condition } \\
4\end{array}$ & $\begin{array}{c}-0.115 \\
(\nabla 610 \mathrm{~m})\end{array}$ & $8.426(\nabla 500 \mathrm{~m})$ & $\begin{array}{c}-1.119 \\
(\nabla 475 \mathrm{~m})\end{array}$ & $14.794(\nabla 375 \mathrm{~m})$ & $14.632(\nabla 375 \mathrm{~m})$ & 9.986 \\
\hline $\begin{array}{l}\text { Condition } \\
5\end{array}$ & $\begin{array}{c}-0.373 \\
(\nabla 335 \mathrm{~m})\end{array}$ & $5.317(\nabla 440 \mathrm{~m})$ & 0 & $16.025(\nabla 370 \mathrm{~m})$ & $15.941(\nabla 370 \mathrm{~m})$ & 11.537 \\
\hline $\begin{array}{l}\text { Condition } \\
10\end{array}$ & 0 & $2.468(\nabla 410 \mathrm{~m})$ & $\begin{array}{c}-0.438 \\
(\nabla 450 \mathrm{~m})\end{array}$ & $11.895(\nabla 355 \mathrm{~m})$ & $11.560(\nabla 355 \mathrm{~m})$ & 9.268 \\
\hline $\begin{array}{l}\text { Condition } \\
11\end{array}$ & $\begin{array}{c}-0.168 \\
(\nabla 610 \mathrm{~m})\end{array}$ & $5.623(\nabla 410 \mathrm{~m})$ & $\begin{array}{c}-0.269 \\
(\nabla 450 \mathrm{~m})\end{array}$ & $9.893(\nabla 355 \mathrm{~m})$ & $9.658(\nabla 355 \mathrm{~m})$ & 7.183 \\
\hline
\end{tabular}

Note. “_" means tensile stress and “+” means compressive stress.

TABle 7: Characteristic stress value of arch dam under special load combination (unit: MPa).

\begin{tabular}{lcccccc}
\hline \multirow{2}{*}{ Working condition } & \multicolumn{2}{c}{ Upstream surface } & \multicolumn{2}{c}{ Downstream surface } & \multicolumn{2}{c}{ Dam toe } \\
& $\begin{array}{c}\text { Minimum } \\
\text { stress }\end{array}$ & $\begin{array}{c}\text { Maximum } \\
\text { stress }\end{array}$ & $\begin{array}{c}\text { Minimum stress of } \\
\text { dam surface }\end{array}$ & $\begin{array}{c}\text { Left abutment } \\
\text { maximum stress }\end{array}$ & $\begin{array}{c}\text { Right abutment } \\
\text { maximum stress }\end{array}$ & Maximum stress \\
\hline Condition 13 & $-1.635(\nabla 332 \mathrm{~m})$ & $5.234(\nabla 470 \mathrm{~m})$ & $0.062(\nabla 560 \mathrm{~m})$ & $16.626(\nabla 375 \mathrm{~m})$ & $15.865(\nabla 375 \mathrm{~m})$ & 11.281 \\
Condition 14 & $-0.053($ dam heel $)$ & $8.862(\nabla 500 \mathrm{~m})$ & $-0.953(\nabla 480 \mathrm{~m})$ & $14.831(\nabla 380 \mathrm{~m})$ & $14.529(\nabla 380 \mathrm{~m})$ & 10.319 \\
Condition 15 & $0.392($ dam heel) & $8.590(\nabla 500 \mathrm{~m})$ & $-1.092(\nabla 480 \mathrm{~m})$ & $14.962(\nabla 380 \mathrm{~m})$ & $14.689(\nabla 380 \mathrm{~m})$ & 9.993 \\
Condition 16 & $-1.539(\nabla 345 \mathrm{~m})$ & $4.894(\nabla 440 \mathrm{~m})$ & 0 & $15.741(\nabla 380 \mathrm{~m})$ & $15.419(\nabla 380 \mathrm{~m})$ & 11.031 \\
\hline
\end{tabular}

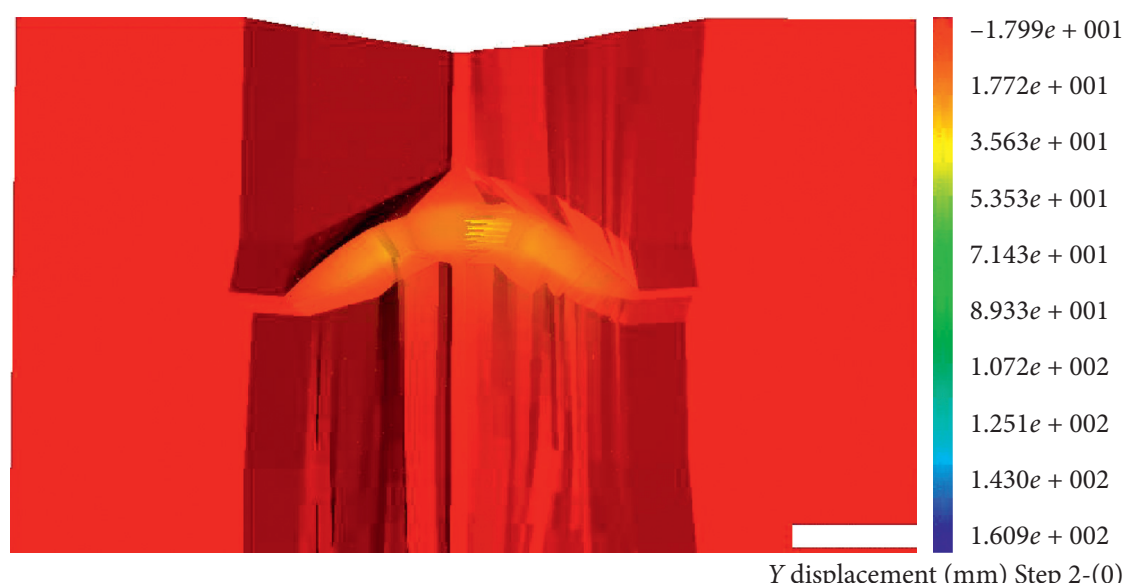

Figure 9: Displacement of foundation along the river in working condition 4 (unit: $\mathrm{mm}$ ).

the foundation was basically in a compression state, the stress distribution on the two banks was basically symmetrical, the additional stress caused by the thrust of the dam body was mainly distributed in the area near the arch abutments, and the stress far away from the dam was controlled by the self-weight stress field of rock mass; only the dam heel of condition 5 had tensile stress.

(2) The calculation results of the special load combination (working conditions 12-16) show that the foundation was basically under compression, the stress distribution on the two banks is basically symmetrical, the additional stress generated by the thrust of the dam body was mainly distributed in the vicinity of the arch abutments, and the stress far away from the dam was controlled by the self-weight stress field of rock mass; only the dam heel of condition 13 had tensile stress.

\subsubsection{Point Safety Analysis of Foundation Surface}

(1) After consolidation grouting, the average elastic modulus of the dam foundation was $12.3 \mathrm{GPa}$ at $0-5 \mathrm{~m}$ and $13.3 \mathrm{GPa}$ at $5-20 \mathrm{~m}$. Combined with the 


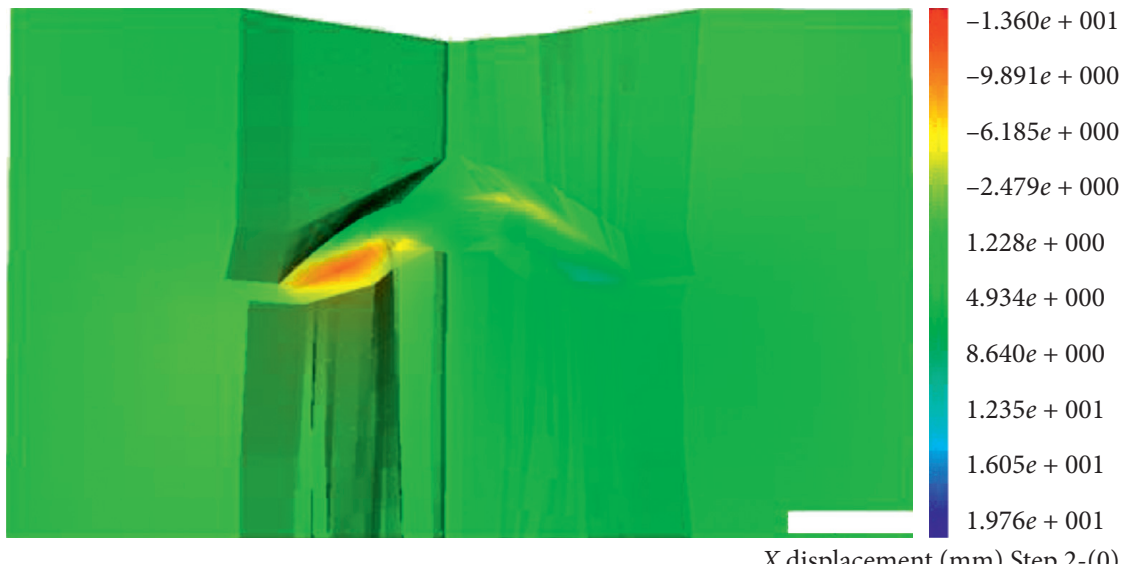

FIgURE 10: Transverse displacement of the foundation under working condition 4 (unit: $\mathrm{mm}$ ).

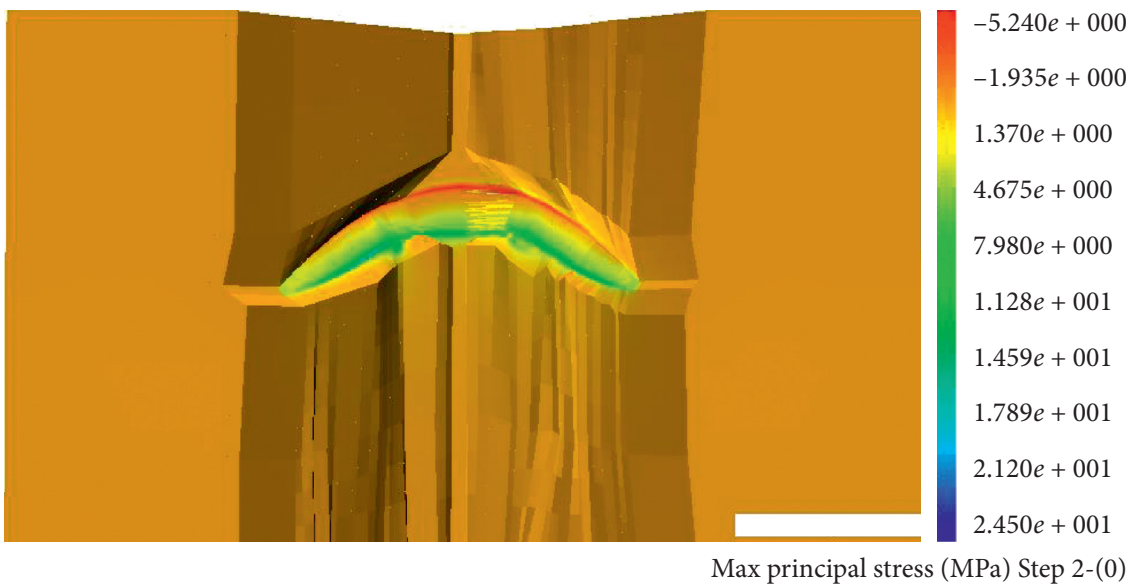

FIGURE 11: Maximum principal stress of foundation under working condition 4 (unit: $\mathrm{MPa}$ ).

current situation of the foundation rock mass, the rock mass evaluation method of layered, segmented, zoned, and graded benchmarking proposed in the design reflected the characteristics of the foundation plane.

(2) Under normal load conditions, the KP of the riverbed was $1.2-3.5$, the point safety degree was small, while the KP of both sides of the riverbed was 1.5-5.0. With the overload increase, the excess force of the riverbed gradually shifts to the sides. Overloading to $3 \mathrm{P0}$, the whole downstream surface $\mathrm{KP}=1.0-1.5$, and the abutment rock mass yielded locally. Overloading to 4P0, the whole downstream surface KP was 1.0-1.5, the riverbed part could still bear large thrust, and a load of dam abutments turned to the riverbed area with higher safety; overloading to $5 \mathrm{P} 0, \mathrm{KP}=1.2$.

(3) Because the foundation of the banks is mainly on class II rock, the riverbed of both banks can still maintain a high degree of safety in the process of overload. Until 3.5-4P0, both banks first yielded.
4.3. Arch Dam Cracking Failure Analysis. In this paper, the RFPA3D code is used to analyze the cracking process of the dam under overload conditions to evaluate the safety of the arch dam. The dam failure under four overload conditions from working conditions 6 to 9 is mainly simulated. The water load is $2,3,4$, and 5 times of normal water load, respectively, and other loads remain unchanged. The yield and cracking state of each elevation of the dam under overload conditions are shown in Table 8 and Figure 13. From the calculation results, the following can be seen:

(1) Under normal load condition (1P0), the dam body did not yield and was in the normal elastic working state. The deformation and stress in the dam and abutment are basically symmetrical. The safety factors of the rock mass near the abutments of the Xiluodu arch dam were greater than 1.0, indicating that the abutments were in a stable state. The value of the stability safety factor of the rock mass near the dam abutments was the same, and that on the surface was lower than the internal rock mass. 


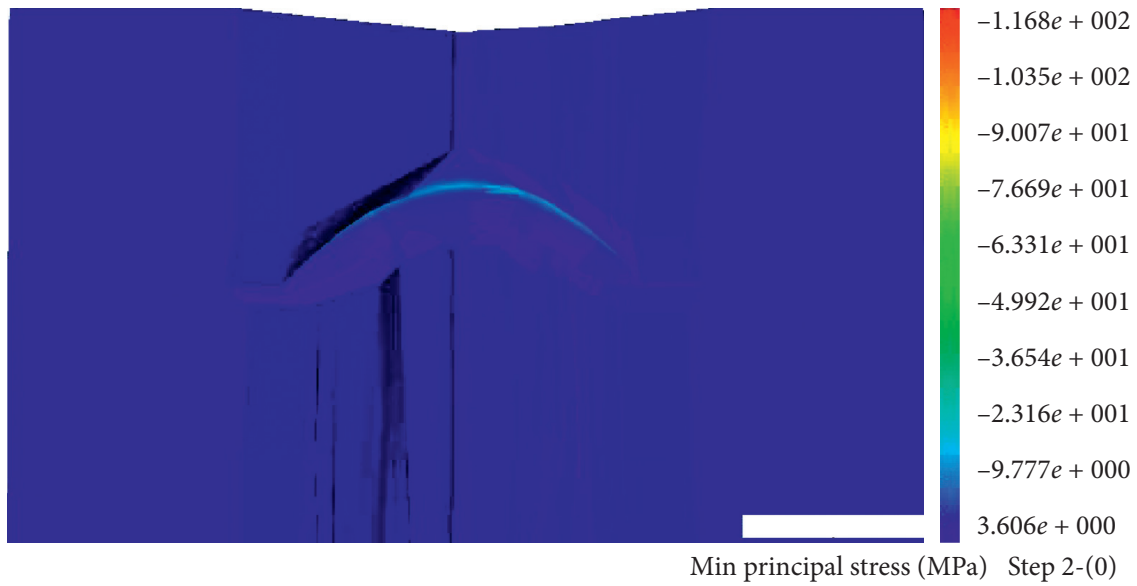

FIgURE 12: Minimum principal stress of foundation under working condition 4 (unit: MPa).

TABLE 8: Yield and cracking state of each elevation of the dam under overload conditions.

\begin{tabular}{|c|c|c|c|c|c|c|}
\hline \multirow{2}{*}{ Position } & & \multicolumn{5}{|c|}{ Load times } \\
\hline & & $1 \mathrm{P} 0$ & $2 \mathrm{P} 0$ & $3 \mathrm{P} 0$ & $4 \mathrm{P} 0$ & $5 \mathrm{P} 0$ \\
\hline \multirow{2}{*}{ EL $610 \mathrm{~m}$} & Upstream dam surface & $\begin{array}{c}\text { Compressive stress, no yield } \\
\text { zone }\end{array}$ & $\begin{array}{l}\text { No yield } \\
\text { zone }\end{array}$ & & Yield $B_{a} / 4$ & Transfixion \\
\hline & $\begin{array}{l}\text { Downstream dam } \\
\text { surface }\end{array}$ & $\begin{array}{c}\text { Compressive stress, no yield } \\
\text { zone }\end{array}$ & $\begin{array}{l}\text { No yield } \\
\text { zone }\end{array}$ & & Yield $B_{a} / 2$ & Transfixion \\
\hline \multirow{2}{*}{ EL $560 \mathrm{~m}$} & Upstream dam surface & $\begin{array}{c}\text { Compressive stress, no yield } \\
\text { zone }\end{array}$ & & & Yield $B_{a} / 8$ & Yield $B_{a} / 8$ \\
\hline & $\begin{array}{l}\text { Downstream dam } \\
\text { surface }\end{array}$ & $\begin{array}{c}\text { Compressive stress, no yield } \\
\text { zone }\end{array}$ & $\begin{array}{l}\text { No yield } \\
\text { zone }\end{array}$ & Local yield & $\begin{array}{c}\text { Cracking } \\
B_{a} / 6\end{array}$ & Split $B_{a} / 4$ \\
\hline \multirow{2}{*}{ EL $520 \mathrm{~m}$} & Upstream dam surface & $\begin{array}{c}\text { Compressive stress, no yield } \\
\text { zone }\end{array}$ & $\begin{array}{l}\text { No yield } \\
\text { zone }\end{array}$ & & & \\
\hline & $\begin{array}{l}\text { Downstream dam } \\
\text { surface }\end{array}$ & $\begin{array}{c}\text { Compressive stress, no yield } \\
\text { zone }\end{array}$ & $\begin{array}{l}\text { No yield } \\
\text { zone }\end{array}$ & $\begin{array}{l}\text { Surface } \\
\text { yield }\end{array}$ & $\begin{array}{c}\text { Cracking } \\
B_{a} / 6\end{array}$ & Split $B_{a} / 3$ \\
\hline \multirow{2}{*}{ EL $460 \mathrm{~m}$} & Upstream dam surface & $\begin{array}{c}\text { Compressive stress, no yield } \\
\text { zone }\end{array}$ & $\begin{array}{l}\text { No yield } \\
\text { zone }\end{array}$ & & & \\
\hline & $\begin{array}{l}\text { Downstream dam } \\
\text { surface }\end{array}$ & $\begin{array}{c}\text { Compressive stress, no yield } \\
\text { zone }\end{array}$ & Yield $B_{a} / 8$ & Yield $B_{a} / 4$ & Yield $B_{a} / 5$ & Yield $B_{a} / 3$ \\
\hline \multirow{2}{*}{ EL $420 \mathrm{~m}$} & Upstream dam surface & $\begin{array}{c}\text { Compressive stress, no yield } \\
\text { zone }\end{array}$ & $\begin{array}{l}\text { No yield } \\
\text { zone }\end{array}$ & & & \\
\hline & $\begin{array}{l}\text { Downstream dam } \\
\text { surface }\end{array}$ & $\begin{array}{c}\text { Compressive stress, no yield } \\
\text { zone }\end{array}$ & $\begin{array}{l}\text { No yield } \\
\text { zone }\end{array}$ & & Yield $B_{a} / 4$ & Yield $B_{a} / 3$ \\
\hline \multirow{2}{*}{ EL $380 \mathrm{~m}$} & Upstream dam surface & $\begin{array}{c}\text { Compressive stress, no yield } \\
\text { zone }\end{array}$ & $\begin{array}{l}\text { No yield } \\
\text { zone }\end{array}$ & & Yield $B_{a} / 4$ & Yield $B_{a} / 3$ \\
\hline & $\begin{array}{l}\text { Downstream dam } \\
\text { surface }\end{array}$ & $\begin{array}{c}\text { Compressive stress, no yield } \\
\text { zone }\end{array}$ & Yield $B_{a} / 6$ & Yield $B_{a} / 8$ & Yield $B_{a} / 8$ & Yield $B_{a} / 6$ \\
\hline \multirow{2}{*}{$\begin{array}{l}\text { Bottom of arch crown } \\
\text { beam }\end{array}$} & Upstream dam heel & $\begin{array}{c}\text { Compressive stress, no yield } \\
\text { zone }\end{array}$ & $\begin{array}{l}\text { No yield } \\
\text { zone }\end{array}$ & Split $B_{a} / 15$ & & \\
\hline & Downstream dam toe & $\begin{array}{c}\text { Compressive stress, no yield } \\
\text { zone }\end{array}$ & $\begin{array}{l}\text { No yield } \\
\text { zone }\end{array}$ & & & \\
\hline
\end{tabular}

Note. " $B_{a}$ " refers to the thickness of the dam body.

(2) Under 2P0, the upstream surface of the dam heel yielded locally, and the dam heel cracked. The downstream surface of the left dam abutment at EL $480 \mathrm{~m}$ yielded and the failure zone increased. The dam surface at EL $560 \mathrm{~m}$-EL $440 \mathrm{~m}$ yielded locally.

(3) Under 3P0, the cracks of the upstream dam heel developed, the cracks of the left dam abutment extended to EL $420 \mathrm{~m}$, and the downstream surface on the left abutment yielded at EL $480 \mathrm{~m}$, resulting in more failure zone. There was a large surface yield area on the left dam surface, and the dam foundation system entered the yield stage.

(4) Under 4P0, the upstream dam heel continued to crack to the two abutments to EL $450 \mathrm{~m}$. The downstream surface of the left dam abutment yielded 


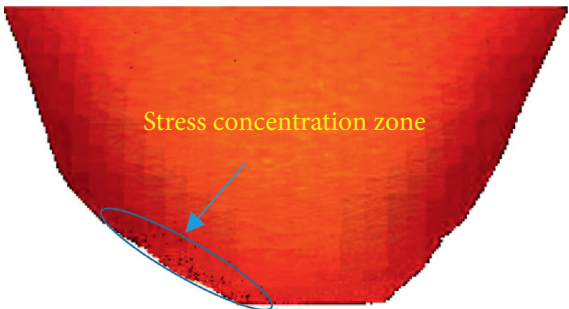

(a)

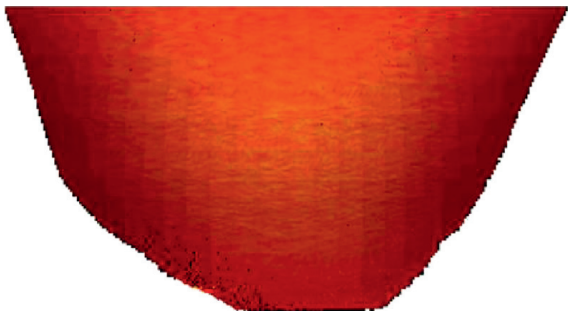

(c)

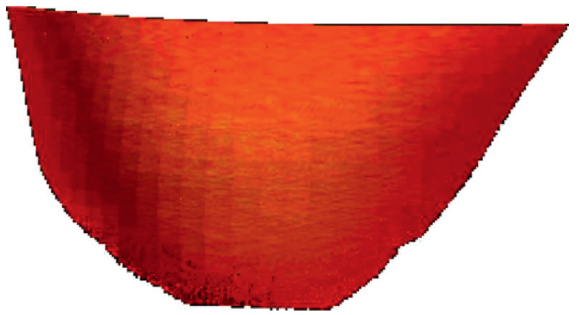

(e)

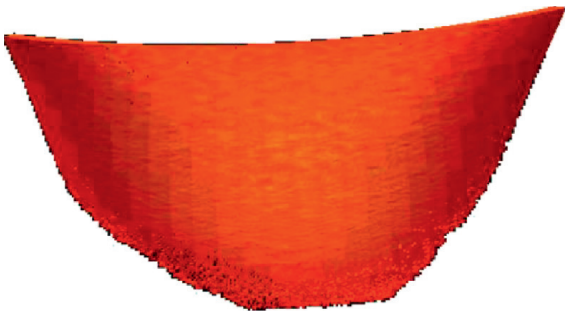

(g)

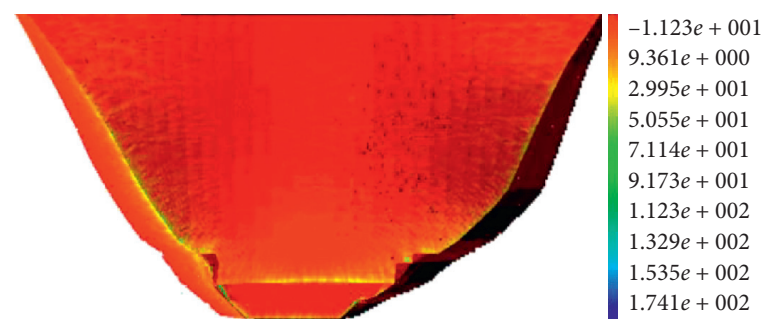

(b)

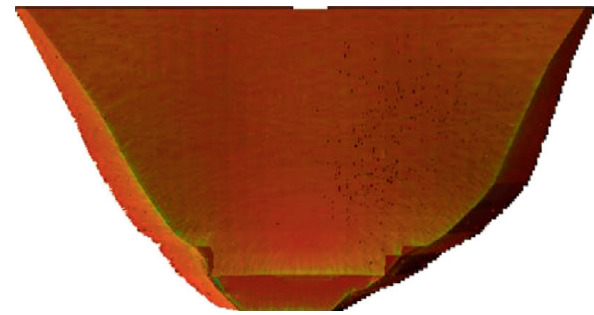

$-1.645 e+001$ $1.369 e+001$ $4.383 e+001$ $7.397 e+001$ $1.041 e+002$ $1.342 e+002$ $1.644 e+002$ $1.945 e+002$ $2.246 e+002$

(d)

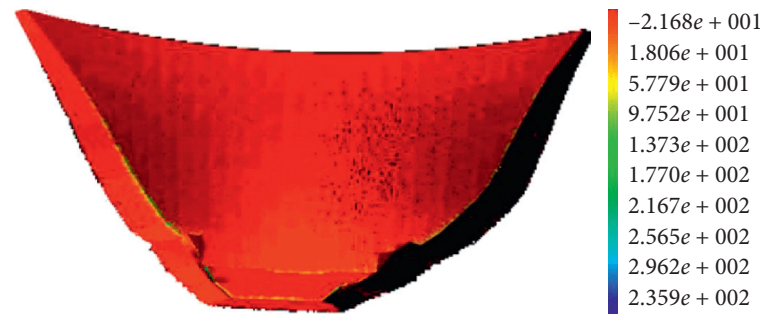

(f)

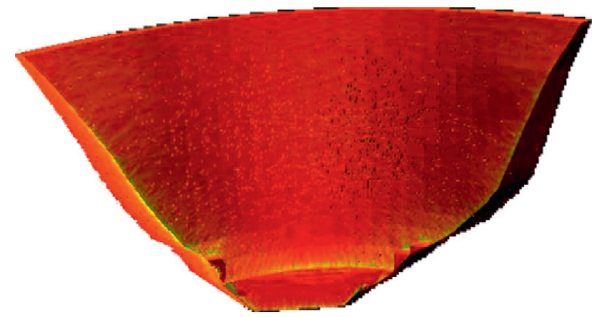

$-2.690 e+001$ $2.239 e+001$ $7.169 e+001$ $1.210 e+002$ $1.703 e+002$ $2.196 e+002$ $2.689 e+002$ $3.181 e+002$ $3.674 e+002$ $4.167 e+002$

(h)

FIGURE 13: Maximum principal stress distribution of Xiluodu arch dam under overload condition (black dot indicates failure zone, unit: MPa). (a) Upstream (2 times normal water load). (b) Downstream (2 times normal water load). (c) Upstream (3 times normal water load). (d) Downstream (3 times normal water load). (e) Upstream (4 times normal water load). (f) Downstream (4 times normal water load). (g) Upstream (5 times normal water load. (h) Downstream (5 times normal water load).

at EL $480 \mathrm{~m}$ and resulted in the increase of the failure zone and tensile stress failure units. The upper and middle parts of the downstream surface yielded and expanded.

(5) Under 5P0, the yield zone at the bottom of the dam body gradually penetrated and extended to the upper-middle elevation of the dam abutments, and the yield range of the upper-middle dam body remained unchanged, with more failure zone and obvious tensile stress failure.

(6) Under 7.5-8P0, the dam became unstable and the natural arch was destroyed.

(7) As shown in Table 9 and Figure 7, with the increase of overload multiple, the variation characteristics of dam structure deformation and characteristic
TABLE 9: Stress and displacement characteristics of the arch dam under overload condition.

\begin{tabular}{lcccc}
\hline Overload multiple projects & 2 & 3 & 4 & 5 \\
\hline $\begin{array}{l}\text { Maximum principal tensile } \\
\text { stress (MPa) }\end{array}$ & -11.23 & -16.45 & -21.68 & -26.90 \\
$\begin{array}{l}\text { Maximum principal } \\
\text { compressive stress (MPa) }\end{array}$ & 174.1 & 254.8 & 335.9 & 416.7 \\
$\begin{array}{l}\text { Maximum displacement } \\
\text { along the river (mm) }\end{array}$ & 296.713 & 439.763 & 582.714 & 725.752 \\
\hline
\end{tabular}

stress are basically linear, without obvious acceleration or sudden change, indicating that the structure could still maintain certain stability before $5 \mathrm{P} 0$. 


\section{Conclusions}

In this paper, the RFPA3D code is used to establish the hexahedron elements of the Xiluodu superlarge model, which realizes the fine simulation of stress and deformation of the dam under layered, overall, multiworking conditions and multistress fields. Based on the calculation results, the following conclusions can be drawn:

(1) Under various working conditions, the displacement distribution of the arch dam body was uniform and symmetrical, the displacement along the river of the arch abutments was equal, and the displacement of the left abutment was slightly larger than that of the right abutment, which stated that the displacement symmetry of dam body was good. In the transverse river direction, the displacement characteristics of the downstream surface of the dam body have little difference, and they were all toward the mountains, so the symmetry of the dam body was good. It can be seen that the homogenization has performed well after the reinforcement treatment of dam abutment rock mass and dam foundation surface. The maximum displacement of the dam foundation is about $27.6 \mathrm{~mm}$, which is equivalent to Ertan and Jinping arch dam, and smaller than the Xiaowan project.

(2) Under normal load, the abutment rock mass was basically under compression; without obvious concentrated stress, the dam body and dam foundation rock mass are in the linear elastic working state. There is a tensile stress area at the upstream arch abutment and the replaced rock mass at the EL $400 \mathrm{~m}-\mathrm{EL} 332 \mathrm{~m}$, the maximum tensile stress is $-1.1 \mathrm{MPa}$ (right arch abutment at EL $380 \mathrm{~m}$ ), and the tensile damage is very small, which will not affect the overall operation of the arch dam. The point safety factor of rock mass and dislocation zone along the bank is more than 1.2 and more than 1.5 in the deep.

(3) Under the condition of temperature rise, the deformation of the abutments increased toward both the mountain and river direction, while the deformation of the arch crown decreased toward both transverse direction and the river direction, which is beneficial to the stability of the arch crown and adverse to the stability of the arch abutments. The tension on the upstream surface made it easier to produce cracks.

(4) The calculation results of various working conditions show that the foundation surface at the dam heel had local yield, and the dam heel cracked. The left dam abutment of the downstream surface yielded at EL $480 \mathrm{~m}$, and the dam body at EL $560 \mathrm{~m}-\mathrm{EL} 440 \mathrm{~m}$ yielded locally. Besides, with the increase of the overload coefficient, the tensile stress failure points increased, and the overall failure zone also increased, but the failure range did not change greatly.
(5) Under overload conditions, the overall overload capacity of the dam abutment rock mass after comprehensive reinforcement was high. The rock mass quality had been improved in the interlayer Lc5 and Lc6 at EL 400-380 m on the left bank and in the dam area near EL $570-520 \mathrm{~m}$ on the right bank.

(6) The overall overload safety degree of the Xiluodu arch dam is obtained as follows: the overload factor of crack initiation $K 1=2 \mathrm{P} 0$, the nonlinear deformation overload factor $K 2=3.5-4 \mathrm{P} 0$, and the limit load factor $\mathrm{K} 3=7.5-8.0 \mathrm{P} 0$. The arch dam has a high degree of overload safety, and dam safety can be satisfied.

(7) The numerical simulation reasonably reflects the stress, deformation, and failure characteristics of dam concrete structure, foundation replacement concrete, dam foundation consolidation grouting, and various rock masses (interlayer dislocation zone, weak structural plane, geological defects) of dam foundation and comprehensively reflects the interaction between arch dam and foundation. The simulation results verify the feasibility of concrete replacement and backfill engineering measures for the Xiluodu arch dam. The stress-strain state and overload capacity of the Xiluodu arch dam are good, which can meet the safety requirements of dam construction. The RFPA3D is used to establish a superlarge fine model to study the working state and overload capacity of the arch dam proposed in this paper, which can be used as a reference for the design and research of super-high arch dam.

\section{Data Availability}

The data used to support the findings of this study are included within the article.

\section{Conflicts of Interest}

The authors declare that they have no conflicts of interest.

\section{Acknowledgments}

This research work was supported by the National Key Research Development Plan (No. 2018YFC1505301) and the Chinese National Natural Science Foundation (Nos. 41941018 and 51627804).

\section{References}

[1] J. P. Zhou, Z. Y. Yang, and G. F. Chen, "Present situation and challenges of high dam construction in China," Journal of Hydraulic Engineering, no. 12, pp. 1433-1438, 2006.

[2] X. Q. Zhou, W. Y. Xu, X. Q. Niu et al., "3D visualization modeling and stability analysis of arch dam and abutment," Rock and Soil Mechanics, vol. 29, no. S1, pp. 118-122, 2008.

[3] H. Zhong, "Large-cale numerical simulation for damage predictionof high arch dams subjected to earthquake shocks," Dalian University Of Technology, PhD Thesis, Dalian, China. 
[4] D. Wang, S. Y. Li, and W. Cao, "ANSYS-based optimal design for shape of arch dams," Journal of Hydro-Science and Engineering, no. 4, pp. 51-55, 2005.

[5] Y. Liu, B. Yang, J. Zhang et al., "Performance simulationbased study on design of super-high arch dam and its application Part I: development status and prospect of structural analysis method for arch dam in China," Water Conservancy and Hydropower Technology, vol. 51, no. 10, pp. 41-54, 2020.

[6] M. Herzog and M. Wang, "Discussion on the damage phenomenon of 20 arch dams (I)," Northwest Hydropower, no. 4, pp. 56-61, 1991.

[7] G. D. Zhang, "Lessons from the failure of malpassit arch dam," Journal of Hydraoelectric Engineering, no. 4, pp. 97-99, 1998.

[8] W. Y. Zhou, X. H. Chen, R. Q. Yang et al., "Experimental study on geomechanical model of overall stability of high arch dam," Water Resources Planning and Design, no. 1, pp. 50-57, 2003.

[9] X. Yu, Y. F. Zhou, and S. Z. Peng, "Stability analyses of dam abutments by $3 \mathrm{D}$ elasto-plastic finite-element method: a case study of Houhe gravity-arch dam in China," International Journal of Rock Mechanics and Mining Sciences, vol. 42, no. 3, pp. 415-430, 2005.

[10] L. Zhang, W. P. Fei, G. L. Li et al., "Experimental study on global geomechanical model for stability analysis of high arch dam foundation and abutment," Chinese Journal of Rock Mechanics and Engineering, no. 19, pp. 67-71, 2005.

[11] X. L. Jiang, J. Chen, S. W. Sun et al., "Experimental study on entire stability for high arch dam," Journal of Yangtze River Scientific Research Institute, vol. 25, no. 5, pp. 88-93, 2008.

[12] W. Y. Zhou, P. Lin, Q. Yang et al., "Experimental research on stability of jinping high slope with three-dimensional geomechanical model," Chinese Journal of Rock Mechanics and Engineering, vol. 27, no. 5, pp. 893-901, 2008.

[13] Q. W. Ren, "Theory and methods of high arch dam's entire failure under disaster conditions," Engineering Mechanics, vol. 28, no. S2, pp. 85-96, 2011.

[14] X. Wang, Y. Liu, Z. Tao, W. Wang, and Q. Yang, "Study on the failure process and nonlinear safety of high arch dam and foundation based on geomechanical model test," Engineering Failure Analysis, vol. 116, Article ID 104704, 2020.

[15] J. L. Yang, H. Zheng, and X. R. Ge, "The analysis of Three dimensional FEM for interaction of the gravity-arch dam and complex ground at Geheyan, Qingjiang River," Rock and Soil Mechanics, no. 4, pp. 5-19, 1989.

[16] F. S. Shen, C. L. Ji, B. Li et al., "Stability analysis of south intake high slope of Xiaolangdi project during completion of construction," Chinese Journal of Geotechnical Engineering, vol. 20, no. 2, pp. 6-9, 1998.

[17] W. Z. Chen, W. S. Zhu, X. B. Qiu et al., "Research on reinforcement scheme for xiaowan abutment," Chinese Journal of Rock Mechanics and Engineering, vol. 21, no. 3, pp. 374-378, 2002.

[18] S. H. Chen, W. M. Wang, M. Y. Xu et al., "Finite element analysis of the crack propagation in high arch dam heel of Xiaowan project," Journal of Hydraulic Engineering, no. 1, pp. 66-71, 2003.

[19] J. T. Wang, J. Yang, J. H. Wang et al., "Simulation of stress distribution and sensitivity analysis on material parameters for high arch dam," Journal of Hydraulic Engineering, vol. 38, no. 7, pp. 832-837, 2007.

[20] L. Zhang, Y. R. Liu, Q. Yang et al., "Global stability of Yangfanggou Arch Dam by 3D nonlinear FEM analysis and geomechanical model tests," Chinese Journal of Geotechnical Engineering, vol. 35, no. S1, pp. 239-246, 2013.

[21] L. Pei, J. S. Zhu, Y. S. Lu et al., "Analysis on stress and deformation behaviors of Lizhou RCC Arch Dam during impounding process," Water Resources and Hydropower Engineering, vol. 46, no. 10, pp. 47-52, 2015.

[22] L. S. Chen and C. C. Li, "On the constitutive relations of rocks," Advances in Mechanics, no. 02, pp. 173-182, 1992.

[23] R. Wang and Y. Q. Yin, "Elastic-plastic constitutive relation of engineering rock medium," Chinese Journal of Mechanics, no. 04 , pp. 317-325, 1981.

[24] F. S. Zhu, "Strength theory and constitutive relation of rock," Mechanics and Practice, no. 5, pp. 9-15, 1997.

[25] C. C. Li, L. S. Chen, H. Li et al., "The constitutive relationship of micro-damage for rock-like brittle material," Rock and Soil Mechanics, vol. 10, no. 2, pp. 55-68, 1989.

[26] J. Xu, S. C. Li, Y. B. Liu et al., "Damage constitutive model of rock based on Drucker-Prager criterion," Journal of Southwest Jiaotong University, vol. 42, no. 3, pp. 278-282, 2007.

[27] Z. Z. Liang, "Threeimensional failure process Analysis of rockand associated numerical tests," $\mathrm{PhD}$ Thesis, Northeastern University, Boston, MA, USA, 2005.

[28] W. C. Zhu, C. A. Tang, T. H. Yang et al., "Constitutive relationship of Mesoscopic elements used inRFPA2D and its validations," Chinese Journal of Rock Mechanics and Engineering, vol. 22, no. 1, pp. 24-29, 2003.

[29] C. A. Tang, "Numerical simulation of AE in rock failure," Journal of Rock Mechanics and Engineering, vol. 16, no. 4, pp. 75-81, 1997.

[30] M. L. Huang, C. A. Tang, and W. C. Zhu, "Numerical simulation on failure process of rock," Chinese Journal of Rock Mechanics and Engineering, vol. 19, no. 4, pp. 468-471, 2000.

[31] Z. Z. Liang, C. A. Tang, Y. B. Zhang et al., "3D numerical simulation of failure process of rock," Chinese Journal of Rock Mechanics and Engineering, vol. 25, no. 5, pp. 931-936, 2006.

[32] W. C. Zhu, C. A. Tang, Q. L. Zhao et al., "Mechanical model and numerical simulation of fracture process of concrete," Advances in Mechanics, vol. 32, no. 4, pp. 579-598, 2002.

[33] C. Tang, "Numerical simulation of progressive rock failure and associated seismicity," International Journal of Rock Mechanics and Mining Sciences, vol. 34, no. 2, p. 249, 1997.

[34] Y. R. Zheng, S. Y. Zhao, and L. Y. Zhang, "Slope stability analysis by strength reduction FEM," Engineering Science, no. 10, pp. 57-61, 2002.

[35] Z. He, S. Y. Zhao, and Y. K. Song, "Advances in theory study and engineering application of wavelet finite element," Chinese Journal of Mechanical Engineering, vol. 41, no. 3, pp. 1-6, 2005.

[36] L. C. Li, C. A. Tang, Z. Z. Liang et al., "RFPA method for slope stability analysis and associated application," Journal of Basic Science and Engineering, no. 4, pp. 501-508, 2007.

[37] Y. B. Zhang, "The research on parallel compuatation method of rock fracture process analysis" $\mathrm{PhD}$ Thesis, Northeastern University, Boston, MA, USA, 2007. 